\title{
Produção e desenvolvimento radicular de plantas de café 'Conilon' propagadas por sementes e por estacas
}

\author{
Fábio Luiz Partelli(1) ${ }^{(1)}$ Henrique Duarte Vieira( ${ }^{(1)}$, Anderson Ribeiro Santiago $^{(1)}$ e Deborah Guerra Barroso ${ }^{(1)}$
}

(1)Universidade Estadual do Norte Fluminense Darcy Ribeiro, Laboratório de Fitotecnia, Av. Alberto Lamego 2000, CEP 28013-602 Campos dos Goytacazes, RJ. E-mail: partelli@yahoo.com.br, henrique@uenf.br, ribeiro@uenf.br, deborah@uenf.br

\begin{abstract}
Resumo - O objetivo deste trabalho foi avaliar a produção e o desenvolvimento radicular e da parte aérea de plantas de café 'Conilon', provenientes de sementes e de estacas, no Município de Vila Valério, ES. Foi utilizado o delineamento experimental em blocos ao acaso com dois tratamentos (mudas provenientes de sementes e de estacas) e 12 repetições com cinco plantas úteis por parcela. As avaliações da parte aérea foram realizadas a partir de sete meses do plantio. Foram realizadas seis desbrotas e cinco colheitas. A avaliação do sistema radicular foi realizada aos 52 meses depois do plantio em quatro profundidades (0-10, 10-20, 20-40 e 40-60 cm). Foram quantificados o diâmetro, o comprimento e a área superficial de raízes. As plantas propagadas por estaca emitiram maior número de ramos plagiotrópicos, durante os sete primeiros meses de idade, e menor número de brotos ortotrópicos durante todo o experimento. Não houve diferenças no comprimento e na área superficial de raízes finas, entre plantas propagadas por sementes e por estacas. Houve maior concentração de raízes finas nas camadas superficiais do solo. A produtividade das plantas propagadas por estacas é maior do que a das plantas propagadas por sementes.
\end{abstract}

Termos para indexação: Coffea canephora, propagação vegetativa, raízes.

\section{Yield and root development of 'Conilon' coffee plants propagated by cuttings and seeds}

\begin{abstract}
The objective of this work was to evaluate the production and root and shoot development of plants of 'Conilon' coffee, grown from seeds and branches, in Vila Valério, ES, Brazil. The experiment was performed in randomized complete block design, with two treatments (seedlings originated from seeds and branches), and 12 replicates with five plants per plot. Shoot growth evaluation was performed seven months after planting. Six pruning of the orthotropic branches and five yields were evaluated. The evaluation of the root system was done 52 months after planting in four depths (0-10, 10-20, 20-40 and 40-60 cm). Diameter, length and superficial area of roots were quantified. Plants grown from cuttings produced more plagiotropic branches, during the first seven months, and less orthotropic branches throughout the experimental period. There were no differences either in length or superficial area of roots from plants propagated by seeds or cuttings. There was a greater concentration of fine roots in the superficial layers of the soil. The productivity of plants grown from cuttings is higher than that observed in plants grown from seeds.
\end{abstract}

Index terms: Coffea canephora, vegetative propagation, roots.

\section{Introdução}

O cafeeiro 'Conilon' (Coffea canephora Pierre) é uma planta diplóide ( $2 \mathrm{n}=22$ cromossomos), auto-estéril e alógama por auto-incompatibilidade do tipo gametofítica (Conagin \& Mendes, 1961). No Brasil, o café é usualmente cultivado em regiões de baixa altitude ( 0 a $400 \mathrm{~m}$ ), principalmente nos Estados do Espírito Santo, Rondônia e Bahia.

As plantas de café 'Conilon', quando propagadas por sementes, apresentam variações quanto à sua arquitetu- ra, produtividade, resistência a doenças e pragas, época de maturação do fruto, tamanho e forma das sementes, frutos e folhas (Conagin \& Mendes, 1961; Bragança et al., 2001).

A propagação vegetativa do café 'Conilon' mantém as características genéticas da planta matriz, o que garante a homogeneidade da lavoura, quanto à maturação de grãos (precoce, médio e tardio) e outras características desejáveis (Weigel \& Jurgens, 2002), e apresenta a vantagem da precocidade inicial da produção (Bragança et al., 2001). Assim, tornou-se vantajosa a propagação 
do cafeeiro 'Conilon' por meio de estacas, razão pela qual os plantios atuais têm sido realizados com a utilização de mudas provenientes de estacas, oriundas de brotos ortotrópicos.

Segundo Lynch (1995), o sistema radicular das plantas apresenta características diferenciadas de acordo com a espécie, variedade, idade da planta, época do ano, clima, densidade de plantio, ataque de pragas, doenças, textura e estrutura de solo, entre outros aspectos. Assim, o conhecimento do sistema radicular de uma espécie é de grande importância para proporcionar um manejo adequado e, quando associado aos fatores edafoclimáticos, é fundamental para a otimização de práticas como calagem e adubação (Caires \& Roselem, 1998; Roselem et al., 2003; Prado \& Natale, 2004), aplicação de produtos fitossanitários, manejo de irrigação entre outras. Além disso, podem ser utilizadas diferentes correlações entre a produção de raízes e a produtividade das plantas. Destaca-se, aqui, a importância da quantidade de raízes, cujo cálculo mostra a capacidade de absorção de água e de nutrientes pela planta (Guimarães et al., 1996).

De acordo com Rena \& Guimarães (2000), o sistema radicular do cafeeiro é pseudopivotante pois, na maioria dos casos, suas raízes pivotantes se apresentam curtas, grossas e terminam abruptamente. Raramente estendendo-se a mais que $45 \mathrm{~cm}$ abaixo da superfície do solo e, freqüentemente, são múltiplas. As raízes, depois dos caules, são os drenos mais fracos do cafeeiro (Cannell, 1971), constituem-se em órgãos de armazenamento de vários nutrientes, em certos momentos fenológicos, além de ter a função de absorção de água e nutrientes, sustentação mecânica da planta e produção de substâncias orgânicas complexas (DaMatta et al., 1999).

Inforzato \& Reis (1963) relatam que 78\% das raízes do cafeeiro 'Arábica', com seis anos de idade, se encontram nos primeiros $30 \mathrm{~cm}$ do solo. Garriz (1978) relata que $60 \%$ das raízes finas $(<2 \mathrm{~mm})$ do cafeeiro 'Bourbon' ficam nos primeiros $20 \mathrm{~cm}$ do solo.

Atualmente, a maioria dos plantios comerciais de café 'Conilon' é realizada com mudas provenientes de estacas; contudo, faltam informações conclusivas quanto ao comportamento comparativo de plantas propagadas por sementes e por estacas e, para estas últimas, há importantes questionamentos quanto ao desenvolvimento da planta, principalmente do sistema radicular, sua capacidade de crescimento em profundidade e sustentação de toda a planta.
O objetivo deste trabalho foi avaliar a produção e o desenvolvimento radicular e vegetativo de plantas de café 'Conilon' provenientes de sementes e de estacas.

\section{Material e Métodos}

O experimento foi conduzido no Município de Vila Valério, noroeste do Estado do Espírito Santo, com altitude de aproximadamente $150 \mathrm{~m}$. O clima é tropical, quente e úmido no verão, com inverno seco. A precipitação anual, média de 1.200 mm, concentrase entre os meses de novembro e janeiro. A temperatura média anual é de $23^{\circ} \mathrm{C}$, e as médias máximas e mínimas são de $29^{\circ} \mathrm{C}$ e $18^{\circ} \mathrm{C}$, respectivamente (Agência Nacional de Águas, 2004). O solo é classificado como Latossolo Amarelo coeso típico (Embrapa, 1999), cujas características físicas e químicas estão descritas na Tabela 1. As análises do solo foram realizadas conforme Silva (1999): pH em água; $\mathrm{P}, \mathrm{Na}, \mathrm{K}, \mathrm{Fe}, \mathrm{Zn}, \mathrm{Mn}$ e Cu pelo extrator Mehlich 1; Ca, $\mathrm{Mg}$ e $\mathrm{Al}$ pelo extrator $\mathrm{KCl} ; \mathrm{H}+\mathrm{Al}$ por meio do extrator SMP; B extraído por água quente; S pelo extrator fosfato monocálcio em ácido acético; matéria orgânica por oxi-

Tabela 1. Características químicas e físicas, de quatro profundidades do solo, em área cultivada com plantas de café 'Conilon', propagadas por sementes e por estacas, aos 52 meses depois do plantio.

\begin{tabular}{lcccc}
\hline Parâmetro & \multicolumn{4}{c}{ Profundidade $(\mathrm{cm})$} \\
\cline { 2 - 5 } & $0-10$ & $10-20$ & $20-40$ & $40-60$ \\
\hline $\mathrm{pH}$ & 6,3 & 6,3 & 5,7 & 5,5 \\
$\mathrm{P}\left(\mathrm{mg} \mathrm{dm}^{-3}\right)$ & 48 & 7 & 2 & 1 \\
$\mathrm{~K}\left(\mathrm{mg} \mathrm{dm}^{-3}\right)$ & 129 & 114 & 57 & 19 \\
$\mathrm{~S}\left(\mathrm{mg} \mathrm{dm}^{-3}\right)$ & 13,7 & 5,8 & 28,8 & 39,0 \\
$\mathrm{Ca}\left(\mathrm{cmol}_{\mathrm{c}} \mathrm{dm}^{-3}\right)$ & 5,2 & 3,2 & 2,0 & 1,6 \\
$\mathrm{Mg}\left(\mathrm{cmol}_{\mathrm{c}} \mathrm{dm}^{-3}\right)$ & 1,2 & 0,4 & 0,2 & 0,1 \\
$\mathrm{Al}\left(\mathrm{cmol}_{\mathrm{c}} \mathrm{dm}^{-3}\right)$ & 0 & 0 & 0 & 0,2 \\
$\mathrm{H}+\mathrm{Al}\left(\mathrm{cmol}_{\mathrm{c}} \mathrm{dm}^{-3}\right)$ & 2,0 & 1,6 & 2,7 & 2,1 \\
$\mathrm{Na}\left(\mathrm{cmol}_{\mathrm{c}} \mathrm{dm}^{-3}\right)$ & 0,06 & 0,05 & 0,04 & 0,03 \\
$\mathrm{SB}\left(\mathrm{cmol}_{\mathrm{c}} \mathrm{dm}^{-3}\right)$ & 6,8 & 3,9 & 2,4 & 1,8 \\
$\mathrm{~T}\left(\mathrm{cmol}_{\mathrm{c}} \mathrm{dm}^{-3}\right)$ & 6,8 & 3,9 & 2,4 & 2,0 \\
$\mathrm{CTC}\left(\mathrm{cmol}_{\mathrm{c}} \mathrm{dm}^{-3}\right)$ & 8,8 & 5,5 & 5,1 & 3,9 \\
$\mathrm{MO}\left(\mathrm{g} \mathrm{dm}^{-3}\right)$ & 29,5 & 15,9 & 11,0 & 7,2 \\
$\mathrm{~m}(\%)$ & 0 & 0 & 0 & 10 \\
$\mathrm{~V}(\%)$ & 77 & 71 & 47 & 46 \\
Fe $\left(\mathrm{mg} \mathrm{dm}^{-3}\right)$ & 18 & 42 & 48 & 24 \\
$\mathrm{Cu}\left(\mathrm{mg} \mathrm{dm}^{-3}\right)$ & 0,4 & 0,4 & 0,4 & 0,4 \\
$\mathrm{Zn}\left(\mathrm{mg} \mathrm{dm}^{-3}\right)$ & 6,9 & 1,1 & 0,3 & 0,3 \\
Mn $\left(\mathrm{mg} \mathrm{dm}^{-3}\right)$ & 17,8 & 7,5 & 1,8 & 0,8 \\
$\mathrm{~B}\left(\mathrm{mg} \mathrm{dm}^{-3}\right)$ & 0,28 & 0,39 & 0,36 & 0,22 \\
Areia total $(\%)$ & 65 & 59 & 55 & 51 \\
Silte $(\%)$ & 12 & 14 & 5 & 3 \\
Argila $(\%)$ & 23 & 27 & 40 & 46 \\
Densidade $\left(\mathrm{g} \mathrm{cm}^{-3}\right)$ & 1,06 & 1,25 & 1,51 & 1,65 \\
\hline
\end{tabular}

MO = matéria orgânica; $\mathrm{SB}=$ soma de bases; $\mathrm{t}$ = capacidade de troca catiônica efetiva; CTC = capacidade de troca catiônica, a pH 7,0; $\mathrm{m}$ = índice de saturação de alumínio; V = índice de saturação de bases. 
dação; granulometria por meio de pipeta e densidade do solo pelo método do anel.

As mudas foram plantadas aos cinco meses e com cinco pares de folhas, e foram obtidas a partir de sementes e de estacas de brotos ortotrópicos de café 'Conilon', de época de maturação intermediária. A lavoura foi plantada no dia 22 de novembro de 1999, com espaçamento de $2 \mathrm{x} 1 \mathrm{~m}$, e o plantio foi conduzido de acordo com as recomendações técnicas para a cultura. A partir do início de 2002, o sistema de adubação deixou de ser o convencional e passou a ser o utilizado em práticas de agricultura orgânica. O delineamento experimental foi o de blocos ao acaso, com dois tratamentos (mudas provenientes de sementes e de estacas) e 12 repetições, com parcela experimental de cinco plantas.

A primeira avaliação da parte aérea foi realizada, quando as plantas estavam com sete meses, tendo sido determinadas a altura da inserção do primeiro par de ramos plagiotrópicos, o número desse tipo de ramos, o comprimento e número dos nós do maior ramo plagiotrópico e a altura da planta. Foi quantificado o número dos brotos ortotrópicos retirados por planta, aos 14, 21, 24, 36, 39 e 49 meses, e o tempo gasto em cada desbrota.

Foram realizadas cinco colheitas nos anos agrícolas 2001 (17 meses), 2002 (29 meses), 2003 (41 meses), 2004 (53 meses) e 2005 (65 meses) e, a partir da produção obtida por planta, foi estimada a produtividade em sacas beneficiadas de $60 \mathrm{~kg} \mathrm{ha}^{-1}$. Os dados referentes à parte aérea do cafeeiro foram submetidos à análise de variância, e as diferenças foram detectadas pelo teste $\mathrm{F}$ a $5 \%$ de probabilidade.

Para a avaliação do sistema radicular das plantas, aos 52 meses depois do plantio, foram retirados monólitos de solo com raízes das 22 unidades experimentais. As amostras foram retiradas a 25 e a $50 \mathrm{~cm}$ de distância do tronco da planta central da parcela, no sentido da entrelinha, por meio de trado tipo sonda, em quatro profundidades (0-10, 10-20, 20-40 e 40-60 cm). O volume dos monólitos retirados nas duas primeiras profundidades foi de $27 \mathrm{~cm}^{3}$ e, nas demais, de $57 \mathrm{~cm}^{3}$. As amostras coletadas foram armazenadas em sacos de plástico e mantidas em câmara fria (aproximadamente $-10^{\circ} \mathrm{C}$ ) até a lavagem, para a separação das raízes que foi realizada sob água corrente, em peneira de 30 mesh. As raízes coletadas pela peneira de 30 mesh foram transferidas para outra de 60 mesh e, novamente, lavadas em água corrente.
As raízes lavadas foram colocadas entre duas placas de vidro (30x21x0,2 cm) e digitalizadas. As imagens foram submetidas ao programa QuantRoot, para quantificação do comprimento, área superficial e diâmetro das raízes, conforme procedimentos adotados por Freitas et al. (2005). Para análise, utilizaram-se as raízes inferiores a $1 \mathrm{~mm}$ de diâmetro, e os dados foram estimados por $\mathrm{cm}^{3}$ de solo.

Foi determinada a distribuição porcentual de raízes no perfil, tendo sido considerada a variação de volume amostrado nas diferentes profundidades.

Os dados de comprimento, área superficial e diâmetro das raízes, por não apresentarem distribuição normal, foram transformados, com o uso da função $y=\log (x+1)$, antes da análise de variância e comparação de médias; entretanto, os dados foram apresentados na forma original.

\section{Resultados e discussão}

Plantas provenientes de estacas emitiram maior número de ramos plagiotrópicos (ramos laterais produtivos), os quais apresentaram maior comprimento e maior número de nós do que as plantas oriundas de sementes (Tabela 2). A altura de inserção do primeiro ramo plagiotrópico foi inferior nas plantas propagadas por estacas, que também apresentaram maior formação de ramos plagiotrópicos próximo ao solo, corroborando os dados de Bragança et al. (2001), que relatam que os ramos plagiotrópicos se formam na axila foliar do primeiro ou do segundo par de folhas das mudas propagadas vegetativamente, e as mudas de semente se formam só depois do nono, décimo ou décimo primeiro par da axila foliar. Com relação à variável altura de planta, não houve diferença entre as plantas produzidas por sementes e por estacas (Tabela 2).

As plantas originadas de sementes produziram maior número de brotos ortotrópicos, nas três primeiras

Tabela 2. Altura da inserção do primeiro par do ramo plagiotrópico, número de ramos plagiotrópicos por planta (NRP), altura da planta, comprimento do maior ramo plagiotrópico e número de nós do maior ramo plagiotrópico, quantificados em cafeeiros 'Conilon' propagados por sementes e estacas, aos sete meses depois do plantio(1).

\begin{tabular}{lccccc}
\hline Tratamento & $\begin{array}{c}\text { Altura } \\
(\mathrm{cm})\end{array}$ & NRP & $\begin{array}{c}\text { Altura da } \\
\text { planta }(\mathrm{cm})\end{array}$ & $\begin{array}{c}\text { Comprimento } \\
(\mathrm{cm})\end{array}$ & $\begin{array}{c}\text { No }^{\circ} \text { de } \\
\text { nós }\end{array}$ \\
\hline Sementes & $30,3 \mathrm{a}$ & $8,9 \mathrm{~b}$ & $50,5 \mathrm{a}$ & $24,7 \mathrm{~b}$ & $4,7 \mathrm{~b}$ \\
Estacas & $8,9 \mathrm{~b}$ & $14,4 \mathrm{a}$ & $47,5 \mathrm{a}$ & $32,1 \mathrm{a}$ & $6,9 \mathrm{a}$ \\
\hline CV $(\%)$ & 14,0 & 4,0 & 7,0 & 6,0 & 8,0 \\
\hline
\end{tabular}

(1)Médias seguidas pelas mesmas letras não diferem entre si pelo teste F, a $5 \%$ de probabilidade. 
desbrotas, realizadas aos 14, 21 e 24 meses depois do plantio (Tabela 3). Com a necessidade de proceder à retirada de maior número de brotos, em relação às plantas originadas de estacas, o tempo gasto foi maior na realização da primeira e terceira desbrotas; todavia, a partir da quarta (36, 39 e 49 meses depois do plantio), o número de brotos ortotrópicos e, conseqüentemente, o tempo gasto para a retirada destes, não foram diferenciados em razão da forma de propagação.

A produtividade das plantas propagadas por estacas foi superior na primeira, segunda e quarta colheitas (Tabela 4). Os valores somados nas cinco colheitas apresentaram superioridade das plantas provenientes de estacas, da ordem de $45 \%$, equivalente a 62,23 sacas beneficiadas de $60 \mathrm{~kg} \mathrm{ha}^{-1}$, o que sugere vantagens da propagação vegetativa do café 'Conilon' sobre a propagação seminal. Esse diferencial de produtividade, principalmente nas primeiras colheitas, pode ser explicado pelo fato de as plantas propagadas por estacas já terem passado pelo estádio juvenil, pois os brotos ortotrópicos, que deram origem a essas plantas, são considerados fisiologicamente adultos (Taiz \& Zeiger, 2002). Esses brotos ortotrópicos são originados de gemas seriadas, que se localizam entre as estípulas e a gema "cabeça-de-série", que formam os ramos plagiotrópicos (Rena et al., 1998). Conforme mostrado, essas plantas emitiram, na fase inicial de crescimento, maior número de ramos e maior número de nós, o que, provavelmente, acarretou maior produção inicial.

Outro fator que pode ter influenciado na maior produtividade das plantas provenientes de estacas é o material genético de boa procedência, cujo processo de clonagem permite maior homogeneidade entre as plantas produzidas e assegura alta qualidade e produtividade (Weigel \& Jurgens, 2002), enquanto as plantas provenientes de semente sofrem variações genéticas que podem reduzir a produção por planta (Conagin \& Mendes, 1961).

No que se refere ao sistema radicular, foi verificada diferença no diâmetro médio das raízes laterais, das plantas propagadas por sementes e por estacas, de 0,355 mm e 0,336 mm, respectivamente, não tendo havido diferenças em função da posição horizontal (distâncias do tronco do cafeeiro) e vertical (em profundidade) das amostragens no perfil. A interação entre as variáveis estudadas (Tabela 5) não foi significativa. Silva \& Rosolem (2002), ao trabalhar com leguminosas, e Rena \& Guimarães (2000), com café 'Arábica', relataram que as raízes apresentam maior diâmetro médio, à medida que aumenta a densidade do solo.

Ao serem analisados os dados referentes ao comprimento e área superficial de raízes produzidas por volume de solo, não foram observadas diferenças entre as formas de propagação (Tabela 6). Assim, fica evidenciado que, nas condições do estudo, o desenvolvimento do sistema radicular do café 'Conilon' foi igual entre as duas formas de propagação.

Não foram verificadas interações entre a distância de coleta ( $25 \mathrm{~cm}$ e $50 \mathrm{~cm}$ do tronco) e a profundidade $(0-10,10-20,20-40$ e $40-60 \mathrm{~cm})$, no que se refere à densidade de área superficial e comprimento das raízes do cafeeiro. Todavia, observou-se maior concentração de raízes na camada superior $(0-10 \mathrm{~cm})$, seguida pelas camadas posteriores na ordem de profundidade, tanto a $25 \mathrm{~cm}$ quanto a $50 \mathrm{~cm}$ (Tabela 7) de distância da planta.

Ao se avaliar o comprimento e a área superficial do sistema radicular, verificou-se diferença estatística entre os perfis amostrados a $25 \mathrm{~cm}$ e $50 \mathrm{~cm}$ do tronco do cafeeiro, entretanto, essas diferenças ocorreram apenas na profundidade de $40-60 \mathrm{~cm}$ (Tabela 7). Esses resultados corroboram, em parte, os apresentados por Inforzato \& Reis (1963) e Garriz (1978), no entanto, neste trabalho, houve maior concentração de raízes nas camadas superficiais do solo (aproximadamente $50 \%$ na camada de $0-10 \mathrm{~cm}$ e mais de $65 \%$ nas camadas de $0-20 \mathrm{~cm}$ de solo), mas, mesmo assim, houve valores próximos a $10 \%$ na camada de 40-60 cm de profundidade (Tabela 8). A menor concentração de raízes em profundidade também foi relatada por Rodrigues et al. (2001), ao

Tabela 3. Número de brotos ortotrópicos retirados e tempo de desbrota despendido por planta de café 'Conilon', proveniente de sementes e de estacas nas desbrotas ${ }^{(1)}$.

\begin{tabular}{|c|c|c|c|c|c|c|c|}
\hline \multirow[t]{2}{*}{ Desbrota } & \multirow[t]{2}{*}{ Idade (meses) } & \multicolumn{3}{|c|}{ Número de brotos retirados } & \multicolumn{3}{|c|}{ Tempo de desbrota por planta (segundos) } \\
\hline & & Sementes & Estacas & $\mathrm{CV}(\%)$ & Sementes & Estacas & $\mathrm{CV}(\%)$ \\
\hline Primeira & 14 & $18,88 \mathrm{a}$ & $8,22 b$ & 13,83 & $4,25 \mathrm{a}$ & $1,55 b$ & 7,34 \\
\hline Segunda & 21 & $9,65 \mathrm{a}$ & $5,42 b$ & 58,21 & $21,62 \mathrm{a}$ & $20,73 a$ & 26,65 \\
\hline Terceira & 24 & $7,06 \mathrm{a}$ & $2,28 b$ & 56,23 & $8,49 \mathrm{a}$ & $6,28 b$ & 29,70 \\
\hline Quarta & 36 & $18,90 \mathrm{a}$ & $16,53 \mathrm{a}$ & 22,47 & $22,78 \mathrm{a}$ & $21,53 \mathrm{a}$ & 20,02 \\
\hline Quinta & 39 & $5,52 \mathrm{a}$ & $5,30 \mathrm{a}$ & 51,86 & $8,13 a$ & $7,68 \mathrm{a}$ & 32,66 \\
\hline Sexta & 49 & $14,65 \mathrm{a}$ & $14,38 \mathrm{a}$ & 38,57 & $22,62 \mathrm{a}$ & $20,97 \mathrm{a}$ & 33,46 \\
\hline
\end{tabular}

(1)Médias seguidas pelas mesmas letras, na linha, não diferem entre si pelo teste $\mathrm{F}$, a 5\% de probabilidade. 
trabalhar com mudas de café cultivadas em diferentes concentrações de alumínio.

As diferenças observadas entre os trabalhos, ocorreram, provavelmente, porque vários fatores podem influenciar o desenvolvimento e a distribuição do sistema radicular tais como: diferenças genéticas; produção e disponibilidade de carboidratos; variação sazonal; tipo de propagação e de formação das mudas; espaçamento do plantio; freqüência de podas aéreas e radiculares; ambiente físico do solo; ambi-

Tabela 4. Produtividade de plantas de café 'Conilon' (sacas beneficiadas de $60 \mathrm{~kg} \mathrm{ha}^{-1}$ ), em cinco colheitas, provenientes de sementes e de estacas ${ }^{(1)}$.

\begin{tabular}{lccccc}
\hline Tratamento & \multicolumn{5}{c}{ Colheita (meses) } \\
\cline { 2 - 6 } & 17 & 29 & 41 & 53 & 65 \\
\hline Estacas & $6,88 \mathrm{a}$ & $90,47 \mathrm{a}$ & $26,72 \mathrm{a}$ & $51,41 \mathrm{a}$ & $25,55 \mathrm{a}$ \\
Sementes & $1,25 \mathrm{~b}$ & $52,81 \mathrm{~b}$ & $20,78 \mathrm{a}$ & $38,57 \mathrm{~b}$ & $25,39 \mathrm{a}$ \\
\hline CV $(\%)$ & 50,15 & 16,92 & 35,26 & 26,23 & 34,87 \\
\hline
\end{tabular}

(1)Médias seguidas pelas mesmas letras não diferem entre si pelo teste F, a $5 \%$ de probabilidade.

Tabela 5. Diâmetro das raízes de plantas de café 'Conilon', propagadas por sementes e por estacas, retiradas a 25 e $50 \mathrm{~cm}$ do tronco, em quatro profundidades ${ }^{(1)}$.

\begin{tabular}{cccc}
\hline $\begin{array}{c}\text { Distância do tronco } \\
(\mathrm{cm})\end{array}$ & $\begin{array}{c}\text { Profundidade } \\
(\mathrm{cm})\end{array}$ & \multicolumn{2}{c}{ Diâmetro das raízes $(\mathrm{mm})$} \\
\cline { 3 - 4 } & $0-10$ & Semente & Estaca \\
\hline 25 & $10-20$ & 0,331 & 0,326 \\
& $20-40$ & 0,351 & 0,311 \\
& $40-60$ & 0,359 & 0,360 \\
& $0-10$ & 0,359 & 0,299 \\
\hline 50 & $10-20$ & 0,334 & 0,319 \\
& $20-40$ & 0,341 & 0,353 \\
& $40-60$ & 0,366 & 0,343 \\
Média & & 0,397 & 0,377 \\
\hline
\end{tabular}

(1)Médias seguidas pela mesma letra não diferem entre si pelo teste $\mathrm{F}$, a $5 \%$ de probabilidade; o coeficiente de variação foi de $18,4 \%$.

Tabela 6. Comprimento e área superficial das raízes de plantas de café 'Conilon' propagadas por sementes e por estacas, retiradas a 25 e $50 \mathrm{~cm}$ do tronco e em quatro profundidades ${ }^{(1)}$.

\begin{tabular}{|c|c|c|c|c|c|c|c|c|}
\hline \multirow{3}{*}{$\begin{array}{l}\text { Profundidade } \\
\quad(\mathrm{cm})\end{array}$} & \multicolumn{4}{|c|}{ Comprimento $\left(\mathrm{m} \mathrm{dm}^{-3}\right)$} & \multicolumn{4}{|c|}{ Área superficial $\left(\mathrm{cm}^{2} \mathrm{dm}^{-3}\right)$} \\
\hline & \multicolumn{2}{|c|}{$\begin{array}{c}25 \mathrm{~cm} \\
\text { do tronco }\end{array}$} & \multicolumn{2}{|c|}{$\begin{array}{c}50 \mathrm{~cm} \\
\text { do tronco }\end{array}$} & \multicolumn{2}{|c|}{$\begin{array}{c}25 \mathrm{~cm} \\
\text { do tronco }\end{array}$} & \multicolumn{2}{|c|}{$\begin{array}{c}50 \mathrm{~cm} \\
\text { do tronco }\end{array}$} \\
\hline & Estaca & $\overline{\text { Semente }}$ & Estaca & $\overline{\text { Semente }}$ & Estaca & $\overline{\text { Semente }}$ & Estaca & Semente \\
\hline $0-10$ & 80,25 & 68,75 & 71,36 & 65,16 & 888,74 & 775,16 & 784,36 & 747,46 \\
\hline $10-2$ & 36,06 & 31,04 & 28,48 & 32,06 & 388,35 & 362,55 & 319,88 & 370,33 \\
\hline $20-40$ & 14,09 & 15,46 & 18,64 & 18,14 & 155,27 & 214,02 & 246,06 & 212,00 \\
\hline $40-60$ & 6,55 & 4,81 & 10,75 & 8,09 & 50,45 & 61,55 & 164,28 & 105,01 \\
\hline
\end{tabular}

(1)Os coeficientes de variação para os dados de comprimento de raiz e área superfical foram de 18,56 e 13,96\%, respectivamente. ente químico do solo (Rena \& Guimarães, 2000); e fatores bióticos como micorrizas (Bressan \& Vasconcellos, 2002).

A redução da densidade das raízes com a profundidade pode ser observada, também, em outras espécies, como demonstrado por Laclau et al. (2001), que estudaram a distribuição espacial de raízes de Eucalyptus spp. Esses autores estimaram que $500 \mathrm{~kg} \mathrm{ha}^{-1}$ de raízes finas estavam em contato com a serrapilheira florestal. Em plantios de cacau, Lehmann (2003) observou que aproximadamente $75 \%$ das raízes finas concentravam-se nos $10 \mathrm{~cm}$ superficiais do solo.

A redução da densidade das raízes finas, em cacau, ocorreu com o aumento da profundidade, em função das características da espécie e seu manejo (Lehmann, 2003) e, neste estudo com café 'Conilon', a redução encontrada (Tabela 7) pode estar associada à baixa fertilidade nas camadas mais profundas do solo (Tabela 1), bem como ao aumento da densidade ao longo do perfil do solo, o que está de acordo com Rena \& Guimarães (2000), que afirmam que a fertilidade pode ser o principal impedimento ao desenvolvimento do sistema radicular do cafeeiro, no Brasil.

Tabela 7. Médias do comprimento e da área superficial das raízes de plantas de café 'Conilon', propagadas por sementes e por estacas, retiradas a 25 e $50 \mathrm{~cm}$ do tronco e em quatro profundidades $^{(1)}$.

\begin{tabular}{crrrrr}
\hline Profundidade & \multicolumn{2}{c}{ Comprimento $\left(\mathrm{m} \mathrm{dm}^{-3}\right)$} & & \multicolumn{2}{c}{ Área superficial $\left(\mathrm{cm}^{2} \mathrm{dm}^{-3}\right)$} \\
\cline { 2 - 3 } & $25 \mathrm{~cm}$ & $50 \mathrm{~cm}$ & & $25 \mathrm{~cm}$ & $50 \mathrm{~cm}$ \\
\hline $0-10$ & $74,50 \mathrm{Aa}$ & $68,26 \mathrm{Aa}$ & & $821,95 \mathrm{Aa}$ & $765,91 \mathrm{Aa}$ \\
$10-20$ & $33,55 \mathrm{Ba}$ & $30,27 \mathrm{Ba}$ & & $375,45 \mathrm{Ba}$ & $345,10 \mathrm{Ba}$ \\
$20-40$ & $14,77 \mathrm{Ca}$ & $18,39 \mathrm{Ba}$ & & $184,64 \mathrm{Ca}$ & $229,03 \mathrm{Ca}$ \\
$40-60$ & $5,68 \mathrm{Db}$ & $9,42 \mathrm{Ca}$ & & $56,00 \mathrm{Db}$ & $134,64 \mathrm{Da}$ \\
\hline
\end{tabular}

(1)Médias seguidas por mesma letra maiúscula, na coluna, e por mesma letra minúscula, na linha, não diferem entre si pelo teste de Tukey a 5\% de probabilidade; os coeficientes de variação, para os dados de comprimento de raiz e área superficial, foram de 18,56 e 13,96\%, respectivamente.

Tabela 8. Porcentagem média das raízes de plantas de café 'Conilon' (comprimento e área superficial), propagadas por semente e estaca, retiradas a 25 e $50 \mathrm{~cm}$ do tronco e em quatro profundidades.

\begin{tabular}{cccccc}
\hline \multirow{2}{*}{$\begin{array}{c}\text { Profundidade } \\
(\mathrm{cm})\end{array}$} & \multicolumn{2}{c}{ Comprimento $(\%)$} & & \multicolumn{2}{c}{ Área superficial (\%) } \\
\cline { 2 - 3 } & $25 \mathrm{~cm}$ & $50 \mathrm{~cm}$ & & $25 \mathrm{~cm}$ & $50 \mathrm{~cm}$ \\
\hline $0-10$ & 50,02 & 44,25 & & 48,96 & 41,66 \\
$10-20$ & 22,52 & 19,62 & & 22,37 & 18,77 \\
$20-40$ & 19,84 & 23,84 & & 22,00 & 24,92 \\
$40-60$ & 7,63 & 12,28 & & 6,67 & 14,65 \\
\hline
\end{tabular}




\section{Conclusões}

1. Plantas propagadas por estacas apresentam produtividade superior às plantas propagadas por sementes.

2. Plantas originadas de sementes emitem maior número de brotos ortotrópicos.

3. Não há diferença no comprimento e na área superficial de raízes finas por volume de solo, entre plantas propagadas por sementes e por estacas.

\section{Agradecimentos}

Ao Sr. Hermes Joaquim Partelli e Valnei Marcos Partelli, pela colaboração nos trabalhos de campo, e por ceder a área para o experimento; ao Professor Alemar Braga Rena, pelas sugestões feitas ao trabalho.

\section{Referências}

AGÊNCIA NACIONAL DE ÁGUAS. A bacia do Rio Doce: características da bacia. Disponível em: <http://www.ana.gov.br/ cbhriodoce/bacia/caracterizacao.asp\#clima>. Acesso em: 6 out. 2004. BRAGANÇA, S.M.; CARVALHO, C.H.S. de; FONSECA, A.F.A. da; FERRÃO, R.G. Variedades clonais de café Conilon para o Estado do Espírito Santo. Pesquisa Agropecuária Brasileira, v.36, p.765770, 2001

BRESSAN, W.; VASCONCELLOS, C.A. Alterações morfológicas no sistema radicular do milho induzidas por fungos micorrízicos e fósforo. Pesquisa Agropecuária Brasileira, v.37, p.509-517, 2002.

CAIRES, E.F.; ROSOLEM, C.A. Correção da acidez do solo e desenvolvimento do sistema radicular do amendoim em função da calagem. Bragantia, v.57, p.175-184, 1998.

CANNELL, M.G.R. Production and distribution of dry matter in trees of Coffea arabica L. in Kenya as affected by seasonal climatic differences and the presence of fruits. Annals of Applied Biology, v.67, p.99-120, 1971.

CONAGIN, C.H.T.M.; MENDES, A.J.T. Pesquisas citológicas e genéticas em três espécies de Coffea; auto-incompatibilidade em Coffea canephora. Bragantia, v.20, p.787-804, 1961.

DaMATTA, F.M.; AMARAL, J.A.T. do; RENA, A.B. Growth periodicity in trees of Coffea arabica L. in relation to nitrogen supply and nitrate reductase activity. Field Crops Research, v.60, p.223229, 1999.

EMBRAPA. Centro Nacional de Pesquisa de Solos (Rio de Janeiro, RJ). Sistema brasileiro de classificação de solos. Rio de Janeiro, 1999. 412p.
FREITAS, T.A.S.; BARROSO, D.G.; CARNEIRO, J.G. de A.; PENCHEL FILHO, R.M.; LAMONICA, K.R.; FERREIRA, D. de A. Desempenho radicular de mudas de eucalipto produzidas em diferentes recipientes e substratos. Revista Árvore, v.29, p.853861, 2005.

GARRIZ, P.I. Distribución radicular de tres cultivares de Coffea arabica L. de 24 anõs de edad, en un suelo limo-arcilloso. Ciencias de la Agricultura, v.2, p.65-76, 1978.

GUIMARÃES, C.M.; BRUNINI, O.; STONE, L.F. Adaptação do feijoeiro (Phaseolus vulgaris L.) à seca. 1. Densidade e eficiência radicular. Pesquisa Agropecuária Brasileira, v.31, p.393-399, 1996.

INFORZATO, R.; REIS, A.J. Estudo comparativo do sistema radicular dos cafeeiros Bourbon Amarelo e Mundo Novo. Bragantia, v.22, p.741-750, 1963.

LACLAU, J.P.; ARNAUD, M.; BOUILLET, J.P.; RANGER, J. Spatial distribution of Eucalyptus roots in a deep sandy soil in the Congo: relationships with the ability of the stand to take up water and nutrients. Tree Physiology, v.21, p.129-136, 2001.

LEHMANN, J. Subsoil root activity in tree-based cropping systems. Plant and Soil, v.255, p.319-331, 2003.

LYNCH, L. Root architecture and plant productivity. Plant Physiology, v.109, p.7-13, 1995.

PRADO, R. de M.; NATALE, W. Calagem na nutrição de cálcio e no desenvolvimento do sistema radicular de goiabeira. Pesquisa Agropecuária Brasileira, v.39, p.1007-1012, 2004.

RENA, A.B.; GUIMARÃES, P.T.G. Sistema radicular do cafeeiro: estrutura, distribuição, atividade e fatores que o influenciam. Belo Horizonte: Epamig, 2000. 80p.

RENA, A.B.; NACIF, A. de P.; GUIMARÃES, P.T.G.; PEREIRA, A.A. Poda do cafeeiro: aspectos morfológicos ecofisiológicos e agronômicos. Informe Agropecuário, v.19, p.61-70, 1998.

RODRIGUES, L.A.; MARTINEZ, H.E.P.; NEVES, J.C.L.; NOVAIS, R.F.; MENDONÇA, S.M. Growth response of coffee tree shoots and roots to subsurface liming. Plant and Soil, v.234, p.207-214, 2001.

ROSOLEM, C.A.; FOLONI, J.S.S.; OLIVEIRA, R.H. de. Dinâmica do nitrogênio no solo em razão da calagem e adubação nitrogenada, com palha na superfície. Pesquisa Agropecuária Brasileira, v.38, p.301-309, 2003.

SILVA, R.H. da; ROSOLEM, C.A. Crescimento radicular da soja em razão da sucessão de cultivo e da compactação do solo. Pesquisa Agropecuária Brasileira, v.37, p.855-860, 2002.

TAIZ, L.; ZEIGER, E. Plant physiology. $3^{\text {rd }}$ ed. Sunderland: Sinauer Associates, 2002. 690p.

WEIGEL, D.; JURGENS, G. Stem cells that make stems. Nature, v.415, p.751-754, 2002. 